\title{
Cem anos de Josué de Castro: legado permanece
}

\author{
Luciana Barreto
}

No ano de seu centenário, celebrar o nome de Josué de Castro ultrapassa a mera saudação ao geógrafo, intelectual, professor e diplomata pernambucano, autor de Geografia da Fome, seu mais célebre livro datado de 1946 e traduzido em mais de 25 idiomas. Seu mérito está inscrito em um amplo e consolidado legado de toda uma vida e obra dedicadas ao combate à fome, verdadeiro libelo que denuncia um dos maiores flagelos da humanidade.

As reflexões levantadas pelo autor repercutem até hoje, em um mundo ainda devastado pelo vergonhoso mal que mina "nossa riqueza humana numa persistente ação destruidora, geração após geração". Suas reflexões e prospecções podem e devem ser retomadas para se conferir importância e vulto político ao primeiro dos Objetivos do Milênio - meta assumida no fórum mundial da Organização das Nações Unidas (ONU), em 2000, onde foi selado o compromisso de redução de $50 \%$ da fome e da miséria no mundo até o ano de 2015.

A Escola Nacional de Administração Pública aproveita a efeméride dos cem anos do nascimento de Josué de Castro para homenageá-lo, reproduzindo, com anuência da Editora Brasiliense e da filha do autor, Anna Maria de Castro, a introdução de Geografia da Fome - O dilema brasileiro: do pão ao aço, lançado em 1946.

Avistar esse horizonte social de bem-estar, qualidade de vida, respeito e dignidade somente é possível demarcando e enfrentando as causas estruturais do subdesenvolvimento econômico e suas nefastas conseqüências da subnutrição, endemias e pobreza generalizada - bandeira assumida pelo governo federal em sua política nacional de segurança alimentar e nutricional, a exemplo do programa Fome Zero e outras ações associadas. Pensamento assimilado, palavra do mestre mantida. 
Introdução do livro "Geografia da Fome - $\mathrm{O}$ dilema brasileiro: do pão ao aço" de Josué de Castro

Hoje, àquelas clássicas imagens se vêm juntar outras de maior atualidade. Imagens dos campos de concentração e das cidades e dos campos europeus devastados pela tirania nazi durante a última guerra mundial. Imagens de homens, mulheres e crianças perambulando como fantasmas num mundo perdido, com os olhos esbugalhados flutuando fora das órbitas e com os molambos de vestuários balançando grotescamente sobre a armação dos esqueletos saltando à flor da pele.

"Quando se lê ou se ouve falar sobre fomes coletivas, sobre angustiadas massas humanas atacadas de epidemias de fome, definhando e morrendo à falta de um pouco de comida, as primeiras imagens que assaltam a nossa consciência de homens civilizados são imagens típicas do Extremo Oriente. Imagens evocativas das superpovoadas terras asiáticas com seus enxames humanos se agitando numa estéril e perpétua luta contra o ameaçador espectro da fome. Massas pululantes de esquálidos coolies chineses. Manchas compactas de ascéticos indianos envolvidos em suas longas túnicas, lembrando uma procissão de múmias. Desesperadas multidões comprimidas nas sinuosas ruelas das cidades orientais, atoladas na lama imunda dos arrozais, asfixiadas de poeira nas estradas da China, estorricadas pelas secas periódicas. Multidões famintas que revelam em seus rostos, em seus gestos e em suas atitudes fatigadas a marca sinistra da fome. Tais são os cenários e os personagens a que nossa imaginação sempre recorreu para dar vida aos dramas da fome coletiva.

Para o leigo, para aqueles que têm conhecimento da fome apenas através do noticiário dos jornais, reduzem-se a estas duas grandes regiões geográficas o Oriente exótico e a Europa devastada as áreas de distribuição da fome, atuando como calamidade social. Infelizmente esta é uma impressão errada, resultante da observação superficial do fenômeno.

$\mathrm{Na}$ realidade, a fome coletiva é um fenômeno social bem mais generalizado. É um fenômeno geograficamente universal, não havendo nenhum continente que escape à sua ação nefasta. Toda a terra dos homens tem sido também até hoje terra da fome. Mesmo nosso continente, chamado o da abundância e simbolizado até hoje nas lendas do Eldorado, sofre intensamente o flagelo da fome. E, se os estragos desse flagelo na América não são tão dramáticos como sempre foram no Extremo Oriente, nem tão espetaculares como se apresentaram nos últimos anos na Europa, nem por isso são menos trágicos, visto que, entre nós, esses estragos se fazem sentir mais sorrateiramente, minando a nossa riqueza humana numa persistente ação destruidora, geração após geração.

É preciso que se confesse corajosamente que a terra da promissão, para a qual foram atraídos, só no século passado, cem milhões de imigrantes europeus, que procuravam fugir às garras da pobreza, também é uma terra onde se passa fome, onde se vive lutando contra a fome, onde milhões de indivíduos morrem de fome. A pouca gente que habita continentes distantes poderia ocorrer a idéia de que a América, com suas enormes reservas naturais, na maior parte inexploradas, com tanta terra à disposição de tão pouca gente e com uma larga faixa do território ocupada pelo povo mais industrioso e ativo do mundo - os americanos do norte - não dispõe do mínimo indispensável 
de alimentos para satisfazer as necessidades de cada um dos seus 350 milhões de habitantes. No entanto, a verdade é que estamos muito longe deste ideal. Os inquéritos sociais e os levantamentos estatísticos levados a efeito em diferentes zonas do continente vieram mostrar que por toda parte as populações americanas continuam expostas às conseqüências funestas da subnutrição e da fome.

Se até quase aos nossos dias o fenômeno não produziu eco é porque as populações da América não se conheciam. América vivia como ilustre desconhecida, muito mais preocupada pelas coisas dos outros continentes, principalmente da fascinante Europa, do que pelos seus próprios problemas. Cada país do continente americano vivendo sua vida fechada, isolando-se uns dos outros, econômica e culturalmente; ignorando-se cordialmente uns aos outros como bons vizinhos discretos e presumidos. Que país americano ousaria confessar que suas populações andavam passando fome, quando seus vizinhos bancavam ares de abundância e de riqueza? Nesta atitude de mascarados, os países da América continuaram escondendo suas misérias, enquanto puderam.

Hoje, com a predominância cada vez mais efetiva das idéias universalistas, da política de portas abertas, estas misérias acabaram por transparecer. Por se apresentarem com inegável evidência, nos dados estatísticos das respectivas produções nacionais e nos diferentes índices reveladores das condições de vida das populações.

Uma das mais graves misérias das terras da América é o estado de fome em que vegetam as populações deste continente. E não só das que vivem na parte mais pobre, ainda não suficientemente explorada, na América latina; mas também na parte mais rica e civilizada, na América
Inglesa. Como veremos oportunamente, numa extensa área dos Estados Unidos da América, no seu velho Sul agrário, continua muita gente a morrer de fome, continuam a manifestar-se entre as populações locais graves doenças, causadas unicamente pela falta de uma alimentação adequada. $\mathrm{Na}$ parte do continente que corresponde à América Latina, o fenômeno ainda é mais grave. Mais de dois terços da população desta área passam fome, sendo que em algumas zonas a fome alcanca três quartas

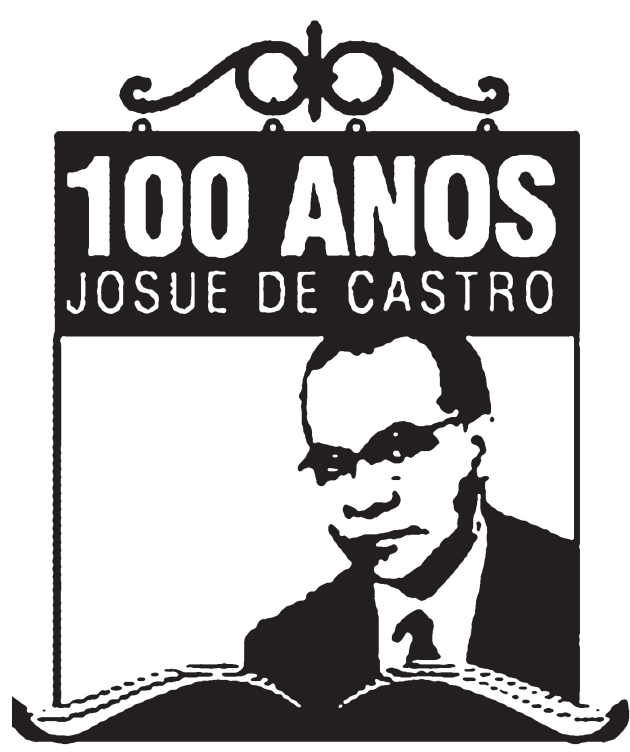

resignação que aproxima, sob este aspecto, os povos americanos dos povos do Oriente. Ambos os continentes - a América nova e a Ásia milenar - têm sofrido resignadamente as suas tragédias de fome. Pretendemos realizar o estudo das diferentes áreas de fome do mundo, iniciandoo com o estudo da fome no Brasil, nosso campo de experiência direta.

A alimentação do brasileiro tem-se revelado, à luz dos inquéritos sociais realizados, com qualidades nutritivas bem precárias, apresentando, nas diferentes regiões do país, padrões dietéticos mais ou menos incompletos e desarmônicos. 
Numas regiões, os erros e defeitos são mais graves e vive-se num estado de fome crônica; noutras, são mais discretos e temse a subnutrição. Procurando investigar as causas fundamentais dessa alimentação em regra tão defeituosa e que tem pesado tão duramente na evolução econômico-social do povo, chega-se à conclusão de que elas são mais produto de fatores sócio-culturais do que de fatores de natureza geográfica.

De fato, com a extensão territorial de que o país dispõe, e com sua infinita variedade de quadros climato-botânicos, seria possível produzir alimentos suficientes para nutrir racionalmente uma população várias vezes igual ao seu atual efetivo humano; e se nossos recursos alimentares são até certo ponto deficitários e nossos hábitos alimentares defeituosos, é que nossa estrutura econômico-social tem agido sempre num sentido desfavorável ao aproveitamento racional de nossas possibilidades geográficas.

A enorme extensão territorial, com seus diferentes tipos de solo e de clima, com seus múltiplos quadros paisagísticos, nos quais vêm trabalhando, há séculos, grupos humanos de distintas linhagens étnicas e de diferentes tintas culturais, não poderia permitir que se constituísse, em todo o território nacional, um tipo uniforme de alimentação. O país está longe de constituir uma só área geográfica alimentar. As variadas categorias de recursos naturais e a predominância cultural de determinados grupos que entraram na formação de nossa etnia nas diferentes zonas tinham que condicionar forçosamente uma diferenciação regional dos tipos de dieta.

O país abrange pelo menos cinco diferentes áreas alimentares, cada uma delas dispondo de recursos típicos, com sua dieta habitual apoiada em determi- nados produtos regionais e com seus efetivos humanos refletindo, em muitas de suas características, tanto somáticas como psíquicas, tanto biológicas como culturais, a influência marcante dos seus tipos de dieta. Cinco áreas bem caracterizadas e assim distribuídas:

1) Área da Amazônia;

2) Área da Mata do Nordeste;

3) Área do Sertão do Nordeste;

4) Área do Centro-Oeste;

5) Área do Extremo Sul. ${ }^{1}$ Felizmente, destas cinco áreas nem todas são a rigor áreas de fome, dentro do conceito que serve de roteiro a nosso trabalho.

Consideramos áreas de fome aquelas em que pelo menos a metade da população apresenta nítidas manifestações carenciais no seu estado de nutrição, sejam estas manifestações permanentes (áreas de fome endêmica), sejam transitórias (áreas de epidemia de fome). ${ }^{2}$ Não é o grau de especificidade carencial que assinala e marca a área, mas a extensão numérica em que o fenômeno incide na população. As áreas culturais, sob quaisquer aspectos em que sejam encaradas, só poderão ser classificadas à base da verificação dos traços predominantes que lhes dão expressão típica, e não de seus traços excepcionais, por mais gritantes que eles se apresentem em sua categoria de exceção. Para que uma determinada região possa ser considerada área de fome, dentro do nosso conceito geográfico, é necessário que as deficiências alimentares que aí se manifestam incidam sobre a maioria dos indivíduos que compõem seu efetivo demográfico.

Das cinco diferentes áreas que formam o mosaico alimentar brasileiro, três são nitidamente áreas de fome: a Área Amazônica, a da Mata e a do Sertão Nordestino. Nelas vivem populações que em grande maioria - quase diria na sua totalidade-exibem permanente ou ciclicamente 
as marcas inconfundíveis da fome coletiva. Nas outras regiões, a do Centro-Oeste e a do Extremo Sul, embora os hábitos alimentares estejam longe de ser perfeitos, não se apresentam, contudo, deficiências alimentares tão pronunciadas, a ponto de arrastarem a maioria da coletividade aos estados de fome. É verdade que também se manifestam nestas áreas os desequilíbrios e as carências alimentares, sejam em suas formas discretas, subclínicas, sejam mesmo em suas exteriorizações completas, mas sempre como quadros de exceção, atingindo grupos reduzidos, representantes de determinadas classes, e não massas inteiras de populações, quase sua totalidade, como ocorre nas três outras áreas alimentares do país. Num rigorismo tecnológico, que se faz necessário, são estas áreas do Centro e do Sul áreas de subnutrição e não propriamente áreas de fome.

Dentro do plano geral de nossa obra, que visa à análise das áreas de fome do mundo, só cabe, pois, o estudo circunstanciado das três primeiras áreas brasileiras, daquelas em que o fenômeno da fome se manifesta numa categoria de calamidade coletiva. Como no estudo da Ar-

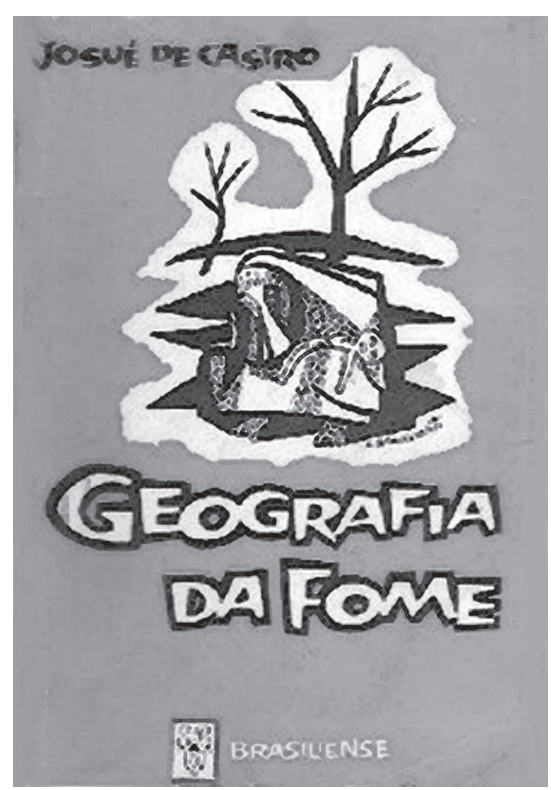

gentina limitamo-nos à análise da região de fome do nordeste andino ou subandino, e nos Estados Unidos, ao da área do Sul, da monocultura do algodão, também no caso brasileiro concentraremos maior interesse na caracterização dessas zonas, onde o fenômeno da fome vem exercendo uma ação despótica, quase determinante, na ronceira evolução social dos grupos humanos que ali vivem.

\section{Notas}

${ }^{1}$ Os limites e a caracterização destas diferentes áreas já foram por nós estabelecidos e publicados em trabalhos anteriores: "As Áreas Alimentares do Brasil" - Resenha Clínico-Cientifica, S. Paulo, abril 1945, e republicada pela América Indígena, volume 5 n 3, México, junho de 1945. Veja-se também Josué de Castro - "The Food Problems in Brazil" - Nutrition Reviews, volume $2, n^{\circ} 2$, março de 1944. Ainda sobre a caracterização das áreas alimentares brasileiras, consulte-se o mapa de "Economia Alimentar no Brasil", organizado por Sálvio Mendonça e incluído no seu livro Noções Práticas de Alimentação, 1938.

2 Os termos "endêmica" e "epidêmica" são aqui empregados em seu sentido mais lato, dentro do moderno conceito de epidemiologia admitido por W. H. Frost. Posta assim de lado a 
definição clássica de C. O. Stallybrass, podemos falar de epidemiologia de fome, do mesmo modo que da do diabetes ou do câncer, defendidas por Wilson G. Smillie em Preventive Medicine and Public Health, Nova Iorque, The Macmillan Company, 1946."

\section{Referência bibliográfica}

1. Brasil - Condições econômicas. 2. Fome. 3. Política nutricional. 4. Subnutrição. 5. Subnutrição - Brasil. I. Título. II. Série Direitos desta edição reservados a Edições Antares.

Castro, Josué, 1908-1973. Geografia da fome: o dilema brasileiro: pão ou aço/Josué de Castro - Rio de Janeiro: Antares: Achiamé, 1980. (Clássicos das Ciências Sociais no Brasil) 